\title{
Evaluating the Age-Energy Consumption Profile in Residential Buildings
}

\author{
Hossein Estiri* \\ Emilio Zagheni ${ }^{\dagger}$ \\ Harvard University, Cambridge University of Washington, Seattle
}

September 5, 2018

\begin{abstract}
Age is an important proxy for many life course trajectories. The relationship between energy consumption and age is complex and understudied. We evaluated the existence and determinants of an age-energy consumption profile in the U.S. residential sector, using microdata from four waves of the Residential Energy Consumption Survey (RECS) in 1987, 1990, 2005, and 2009. We constructed pseudo cohorts from Bayesian generalized linear model estimates to draw micro-profiles for energy consumption across the life course. Overall, we found that residential energy consumption increases over the life course. Much of the increase in energy consumption is due to housing size. Variations in the the age-energy consumption micro-profiles can be described by concave and convex functions. In contrast to previous research that suggested that population aging would reduce energy demand, our results indicate that changing population age structure could amplify residential energy demand.
\end{abstract}

*hestiri@hms.harvard.edu

†emilioz@uw.edu 


\section{Introduction}

Energy is a key driver of our societies. Every community, every building, and every business relies on energy, and our dependence on energy is only increasing. Despite all the technological advancements in energy efficiency, by 2040 world energy consumption is expected to be about 60 percent higher than its 2010 level [41]. With about 40 percent share in global energy demand [22, 24, 27, 31], buildings are the world's largest energy consumers. Residential buildings use most of this global share. Nonetheless, we know very little about the processes that drive energy demand in buildings. On the one hand, the residential building energy debate has often neglected the role of occupants by excessively focusing on technical and physical attributes of the buildings $[3,17,20]$. On the other hand, energy demand studies that focus on sociodemographic attributes have often downplayed the role of household-housing interactions [9]. Proper understanding of the patterns and drivers of residential energy demand is important for economic growth, energy justice, natural resource conservation, and climate change policy.

According to the United Nations, population aging is one of the most prominent demographic transformations of the current century [34]. Age is an important yet puzzling factor in determining events across the life course. We know about the correlation between age and many sociodemographic variables (e.g., income and household size) and corresponding consequences on consumption behaviors like housing needs, residential mobility, or energy demand. However, due to the lack of longitudinal data and several confounding variables, isolating consumption patterns to understand the role of age across the life course is difficult. In this paper we aim to test a primary hypothesis that energy consumption increases over age, irrespective of climate, income, and housing characteristics. To test this hypothesis, we develop a methodology for estimating energy consumption by age groups and use the estimates to construct an age-energy consumption profile. We also explore the potential impact of housing characteristics, income, and climate regions on the age-energy consumption profile.

\section{Background}

In combination with technology, age of the structure and building size and type are the most important physical determinants of energy consumption in buildings. Previous research has shown that older $[5,14,28,9,10,18]$, larger $[19,29,12,9]$, detached housing units $[12,18,16,7,28,3]$ consume more energy than newer, smaller, multifamily housing units. These physical factors, however, work in tandem with households' sociodemographic characteristics $[8,9,11]$.

Socio-economic status and life cycle variables have received substantial attention in social research. Income has a prominent positive association with increasing residential 
energy consumption [2, 6, 21, 25, 42]. Attitudes toward the use of home appliances, and thus energy consumption, are related to lifestyles. Differences across lifestyle can be attributed to households' lifecycle [43, 23]. The lifecycle approach in demography considers age as an underlying determinant of household characteristics, needs, preferences, and attitudes.

Prior research has shown that age of residents predicts residential energy consumption behaviors as well as their income does [4]. Older households are mostly expected to consume more energy [3, 14, 33, 43]. However, the relationship between household lifecycle and energy consumption is not linear, as the growing trend decreases over time. Overall, middle-aged, married households with children have the highest energy consumption, compared with households at earlier and later lifecycle stages [13].

Like most other sociodemographic determinants of energy consumption, the effects of income and age on energy consumption are intertwined with other factors such as housing characteristics $[19,30,26,1,9,11]$. The elderly show different attitudes in the use of appliances and housing choices (e.g., they may live in old owned homes) than the younger households, and therefore their energy consumption is different [43].

As population is aging globally [34], a better understanding of the role of age as a driver of energy demand can create potentials to align climate change, energy, and population policies for higher effectiveness. Given the relationship between age and sociodemographic and housing characteristics, it is not clear as to what extent age can determine residential energy consumption.

\section{Data}

We used public microdata from four waves of the Residential Energy Consumption Survey (RECS) in 1987, 1990, 2005, and 2009. Selection of these four waves was due to the availability of data elements across surveys - the four surveys consistently contained all variables of interest. Designed by the Energy Information Administration (EIA), RECS is a national survey that has collected energy-related data for housing units occupied as a primary residence and the households that live in them.

Households for the surveys are sampled at random using a complex multistage, areaprobability design. The 1987 and 1990 surveys contain data from 6,229 and 6,095 households, weighted to respectively represent 90.5 and 94 millions of households in the 50 States and the District of Columbia, as of November 1987 and 1990 [38, 37]. The 2005 and 2009 surveys collected data from 4,382 and 12,083 households, respectively representing 111.1 millions and 113.6 millions U.S. households [39, 40]. We conducted substantial data processing steps to prepare a harmonized dataset across surveys for our analyses - data and analytic code are available on project's GitHub page. To isolate the potential behavioral differences in consumption of residential energy among 
renters and home owners, we only used the subset of data that represent owner-occupied housing units. Table 1 (Appendix) contains the list and description of variables used in this study.

\section{Estimating the Age-Energy Consumption Pro- file}

The RECS data provide energy consumption at the household/housing unit level. The four waves selected for this study also provide information on the number and age of household members. We constructed the age-energy profiles by estimating individual level energy consumption coefficients based on the theoretical model proposed by Zagheni (2011) [44].

Let $c_{i}$ be the energy consumption by household $i$. Then,

$c_{i}=\sum_{k=1}^{M} c_{i k}$

where $c_{i k}$ is the energy demand for the $k$ th member, and $M$ is the total number of people in the household $i$.

The energy consumption for each individual is a function of age groups. We defined 17 5-year age groups (i.e., 0-4, 5-9, ...,75-79, and 80 plus). Each age group has its own consumption parameter, such that an individual energy demand is given by

$c_{i k}=\beta_{1} \operatorname{Ind}(1)_{k}+\beta_{2} \operatorname{Ind}(2)_{k}+\ldots+\beta_{17} \operatorname{Ind}(17)_{k}$,

where

$\operatorname{Ind}(X)_{k}=\left\{\begin{array}{c}1 \text { if age of member } k \text { belongs to age group } X \\ 0 \text { otherwise }\end{array}\right.$

The parameter $\beta_{X}$ is the consumption by a person in age group $X$. Given the two equations, the equation for total energy consumption by household $i$ (dependent variable) becomes:

Model 1: $c_{i}=\beta_{1} \sum_{k} \operatorname{Ind}(1)_{k}+\beta_{2} \sum_{k} \operatorname{Ind}(2)_{k}+\ldots+\beta_{17} \sum_{k} \operatorname{Ind}(17)_{k}$,

or in the short form, 
Model 1: $c_{i}=\sum_{X=1}^{17} \beta_{X} \sum_{k} \operatorname{Ind}(X)_{k}$

This equation is our base model, Model 1. We estimated $\beta$ s by Bayesian generalized linear modeling. We then visualized parameters $\beta_{1}$ to $\beta_{17}$ to construct a series of ageenergy consumption micro-profiles. However, as discussed earlier, since there are more factors influencing energy consumption in a residential buildings, it is likely that our base model presents an oversimplification of residential energy demand. To address this issue, we introduced new predictors (including household income and housing physical characteristics) and evaluated improvements in overall model fit and changes in the micro-profiles obtained from Model 1, when accounting for other factors. We built 7 nested models on top of Model 1: 1) Model 2 added local climate to Model 1,2) Model 3 added income to Model 2, 3) Model 4 added housing type to Model 3,4) Model 5 added housing age to Model 4,5) Model 6 added square root of housing size to Model 5,6 ) Model 7 added income to Model 6, and 7) Model 8 added housing type and age to Model 7. Together, we built eight models for each survey wave - total of 24 Bayesian generalized linear model. To study the role of local climates, we developed additional models for three regional climates.

\subsection{Model Comparison}

To compare the models and limit the number of models for interpretations, we used an approximation to Leave-One-Out (LOO) cross-validation and selected the model(s) with the highest expected log predicted density (elpd).

\section{Constructing Pseudo Cohorts}

We constructed pseudo cohorts by following age groups in the 1987 wave all the way to the 2009 wave. Using the 1987 age groups as the baseline, we were able to create pseudo-cohorts of individuals who were less than 60 years old in the 1987 survey - for older individuals we do not have reliable data in the 2009, which is the latest survey wave we used. For example, the first cohort is constructed from those who where five years old or younger in 1987, between five and nine in 1990, between 20 and 24 in 2005, and between 2005 and 2009 in 2009 - see supplementary materials for details. This process resulted in construction of 12 pseudo cohorts. We used the pseudo cohorts to address the research questions. 


\section{$6 \quad$ Results}

We describe the results in four parts. First, we describe the model selection results. Second, we evaluate the primary hypothesis by interpreting the estimated coefficients for pseudo cohorts obtained from the best model. Third, we examine the role of housing and income predictors in shaping the age-energy consumption profile. Fourth, we further explore regional climate's impacts on the age-energy consumption profiles.

\subsection{Model Selection}

The log predicted density (elpd) for each model is plotted in (Figure 1). In our four waves, there was a significant bump in elpd when local climate variables (heating- and cooling-degree days) were added in model 2. We used model 2 as the baseline model. Additionally, models 3 (baseline model + income) and 6 (baseline model + housing size) improved the elpd significantly from their prior Models. Using the elpd results from each models, we basically eliminated models 1, 4, and 5 from the interpretation process as they did not produce better models.

\subsection{Is there an age-energy consumption profile?}

Using the outputs from the top model (Model 8), we plotted the estimated coefficients and connected the point estimates with a Loess smoothed line for each pseudo cohort to visualize a hypothetical age-energy consumption profile out of the 12 pseudo cohort micro-profiles (Figure 2). With 2,000 iterations of the Bayesian generalized linear model, we obtained 6,000 point estimated and a median for each age group. Individual estimates are plotted in gray and the Loess smoothed lines connecting the pseudo cohort medians (pseudo cohort micro-profiles) are color coded in Figure 2.

In general, the results provided support for our hypothesis that there is an age-energy consumption profile. As Figure 2 shows, the age-energy consumption profile presented an almost-linear growth in energy consumption over age. The pseudo cohort microprofiles provide detailed information about how the general age-energy consumption profile is shaped. We found two prevailing patterns in terms of concavity and convexity in the energy consumption micro-profiles: 1) a convex function for the three youngest pseudo cohorts, and 2) a concave function for the older seven pseudo cohorts. That is, generally the energy consumption has a decrease-increase patterns for people younger than 39. Assuming the age of 19 as when youngsters tend to decrease their dependence to their families, there is a reduction in their energy consumption pretty much through their 20s. This could be resulted from usually smaller households and often lower levels of housing needs during this period. 


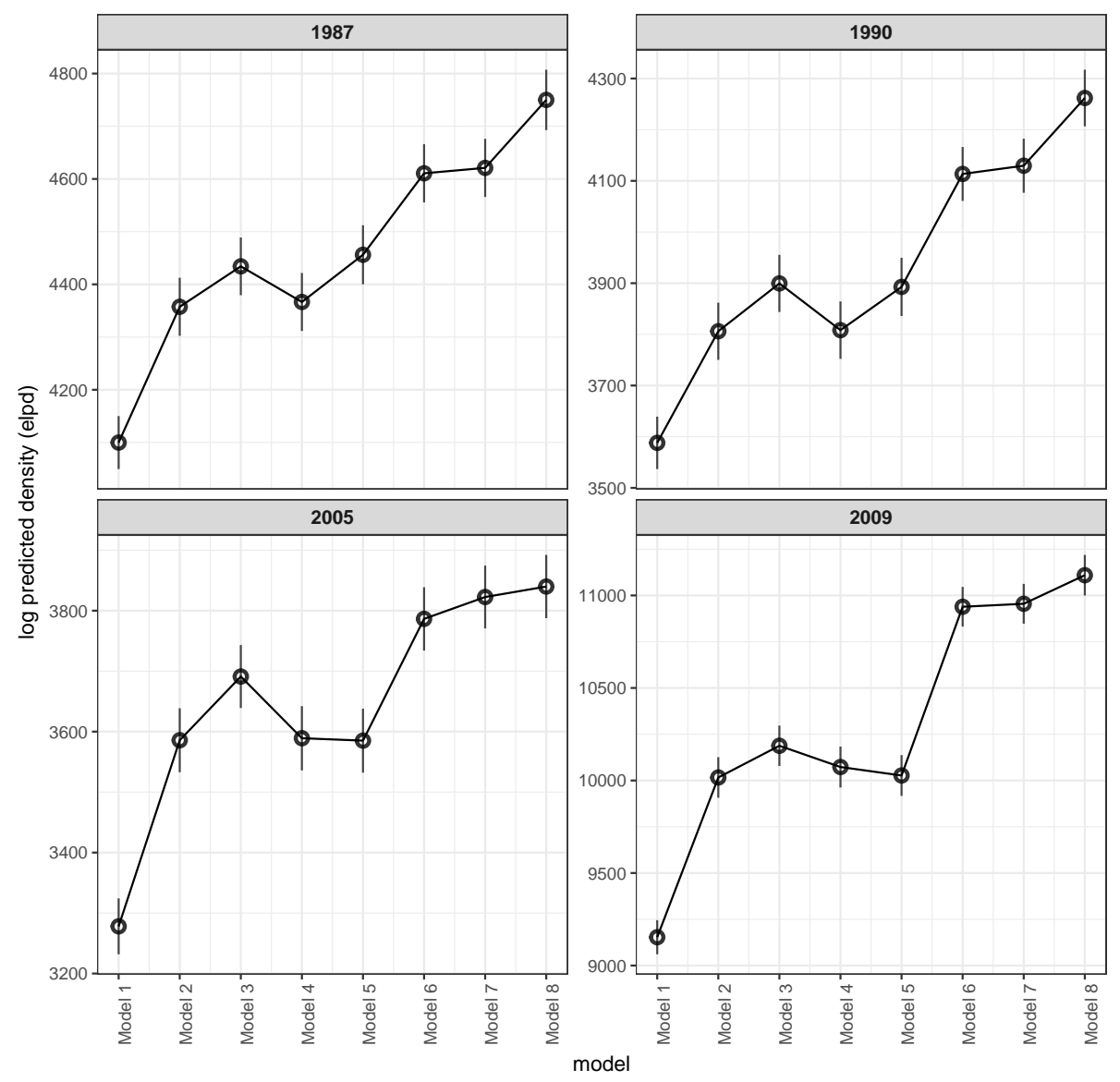

Figure 1: Log predicted density (elpd) for Models 1 to 8

The 30s is the beginning of an upward sloping curve in age-energy consumption microprofiles, where a peak energy consumption is reached around the age of 55. Immediately following the peak energy consumption, the micro-profiles exhibited decrease in energy consumption, forming concave functions (i.e., increase-decrease patterns) - with the exception of the eldest pseudo cohort. While the overall pattern suggested a slight decrease in energy consumption between the ages of 60 and 80, the eldest pseudo cohort that included people older than 80 in 2009 demonstrated an increasing concave micro-profile, suggesting that energy consumption increases in elderly population.

\subsection{Does housing and income matter?}

Now that we were able to observe a general age-energy consumption profile, we use the outputs from all the selected models to explore whether housing and income influence the age-energy consumption profile (Figure 3). As discussed in the model selection, Models 4 and 5 did not improve the model performance metrics, and therefore their 

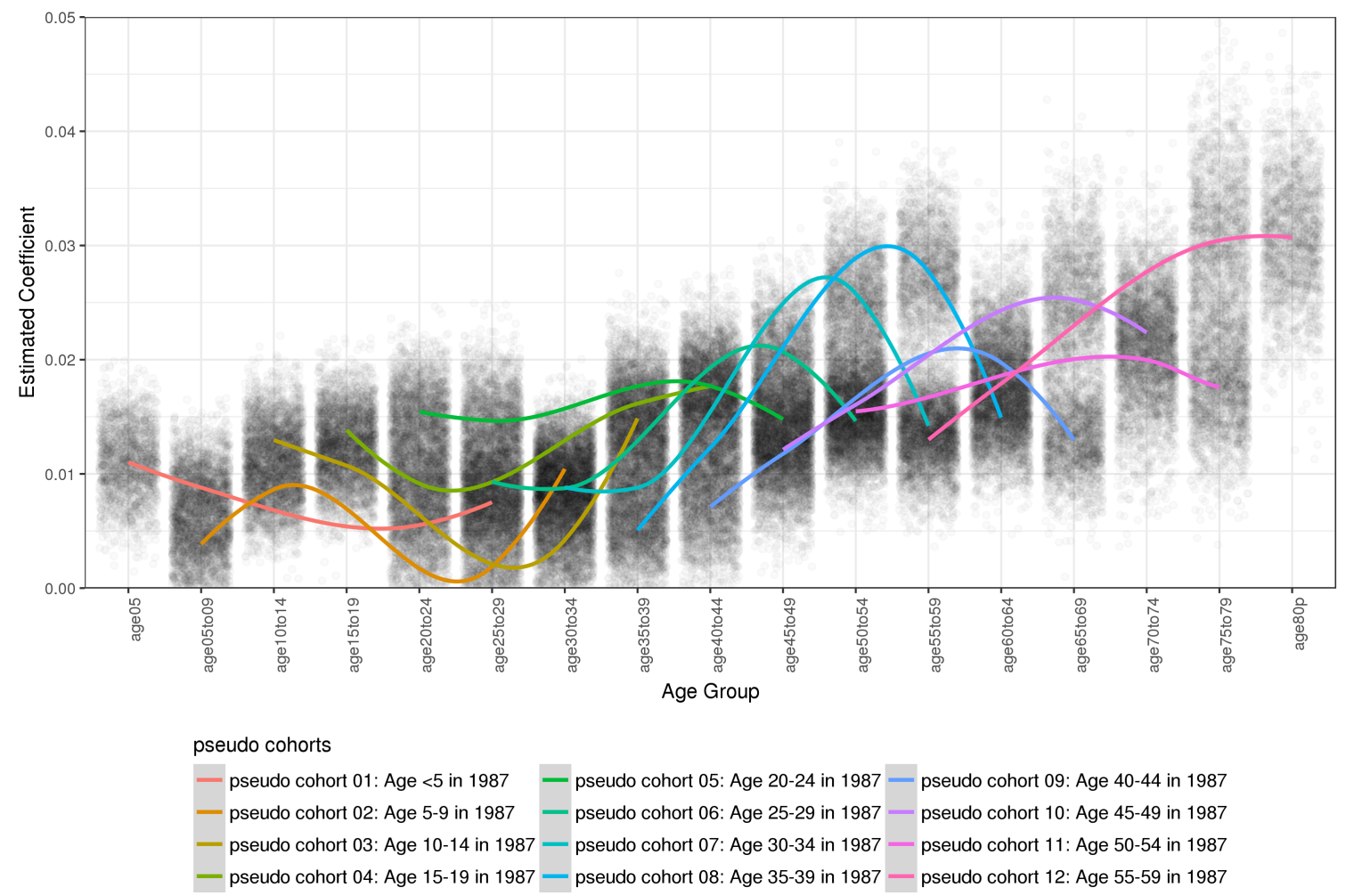

Figure 2: The pseudo cohort age-energy consumption micro-profiles drawn from the top Bayesian generalized linear model.

individual impacts on the age-energy consumption profile were minimal. As Figure 3 illustrates, the overall age-energy consumption profile showed a bolder increasing pattern between ages of 30 and 55, before accounting for income and housing conditions (the first plot on the left in Figure 3). The main impact of adding income to the baseline model (i.e., Model 3) resonated in changing the overall age-energy consumption profile after the age of 55 from a diminishing trend to a boosting trend. That is, holding income constant, people increasingly consume more energy after the age of 55 . We can interpret the income's effect as revealing a biological increase in energy demand as we age.

Accounting for income did not change the magnitude of coefficients significantly. However, adding housing size variable to the baseline model explicitly decreased the coefficients' size, particularly after the age of 30. In addition, accounting for housing size decreased the slope of the increasing trend after the age of 30 . This finding is important as it suggests that much of the increase in energy consumption after the age of 30 can be attributed to an increase in housing size, which is expected as households grow. Models 7 (baseline+income+housing size) and 8 (baseline+income+housing size+housing age+housing type) did not present significant deviations from Model 6, further highlighting the impact of housing size on age-energy consumption profile. 

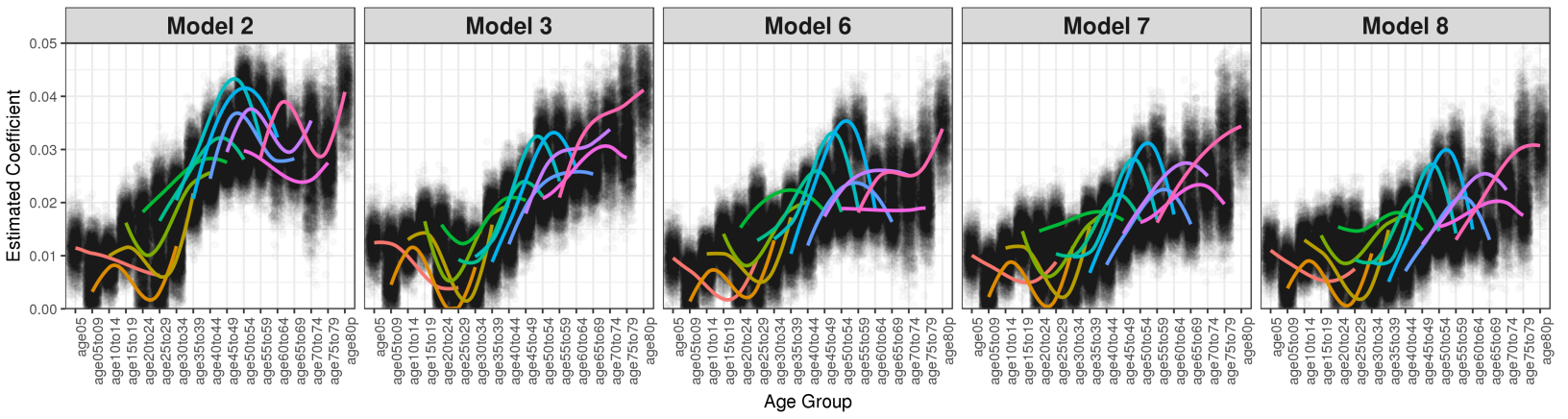

pseudo cohorts
— pseudo cohort 01: Age <5 in $1987 \quad$ - pseudo cohort 04: Age 15-19 in 1987 — pseudo cohort 07: Age 30-34 in 1987 — pseudo cohort 10: Age 45-49 in 1987
— pseudo cohort 02: Age 5-9 in $1987 \quad$ - pseudo cohort 05: Age 20-24 in 1987 — pseudo cohort 08: Age 35-39 in 1987 — pseudo cohort 11: Age 50-54 in 1987
— pseudo cohort 03: Age 10-14 in 1987 — pseudo cohort 06: Age 25-29 in 1987 — pseudo cohort 09: Age 40-44 in 1987 — pseudo cohort 12: Age 55-59 in 1987

*Model 2: the baseline model (includes local climate variables), Model 3: baseline+income, Model 6: baseline+housing size, Model 7: baseline+income+housing size, Model 8: all predictors.

Figure 3: Changes in age-energy consumption micro-profiles across models.

For a closer comparison, we plotted the micro-profiles for each pseudo cohort across models in Figure 4. We found that the micro-profiles are almost the same (both in magnitude and form) for pseudo cohorts 2 and 3, who were between 5 and 14 years old in 1987. This finding suggested that neither income nor housing variables impacted the age-energy consumption profiles for the youngster. For the youngest pseudo cohort, however, introduction of income and housing variables changed a slightly diminishing profile obtained from the baseline model to a decrease-increase pattern that would align well with the proceeding cohorts.

Between the pseudo cohorts 5 and 8, which included people of ages 20 to 39 in 1987 (encompassing the peak energy consumption cohorts), the main effect of accounting for income and housing variables was in the magnitude of the coefficients. This finding suggests that much of the consumption of energy between the ages of 20 and 60 can be attributed to income and housing characteristics, but the general form would hold.

In terms of the form of the age-energy consumption profile, most of the variance can be discovered in the last four pseudo cohorts. As presented in Figure 4, micro-profiles obtained from the baseline model altered both in form and magnitude (specially in form) from the micro-profiles obtained from models with income and housing characteristics for the elderly. Where the baseline model suggested a decrease-increase trend after the age of 60 , we found that energy consumption would continue to increase after holding income and housing characteristics constant. 


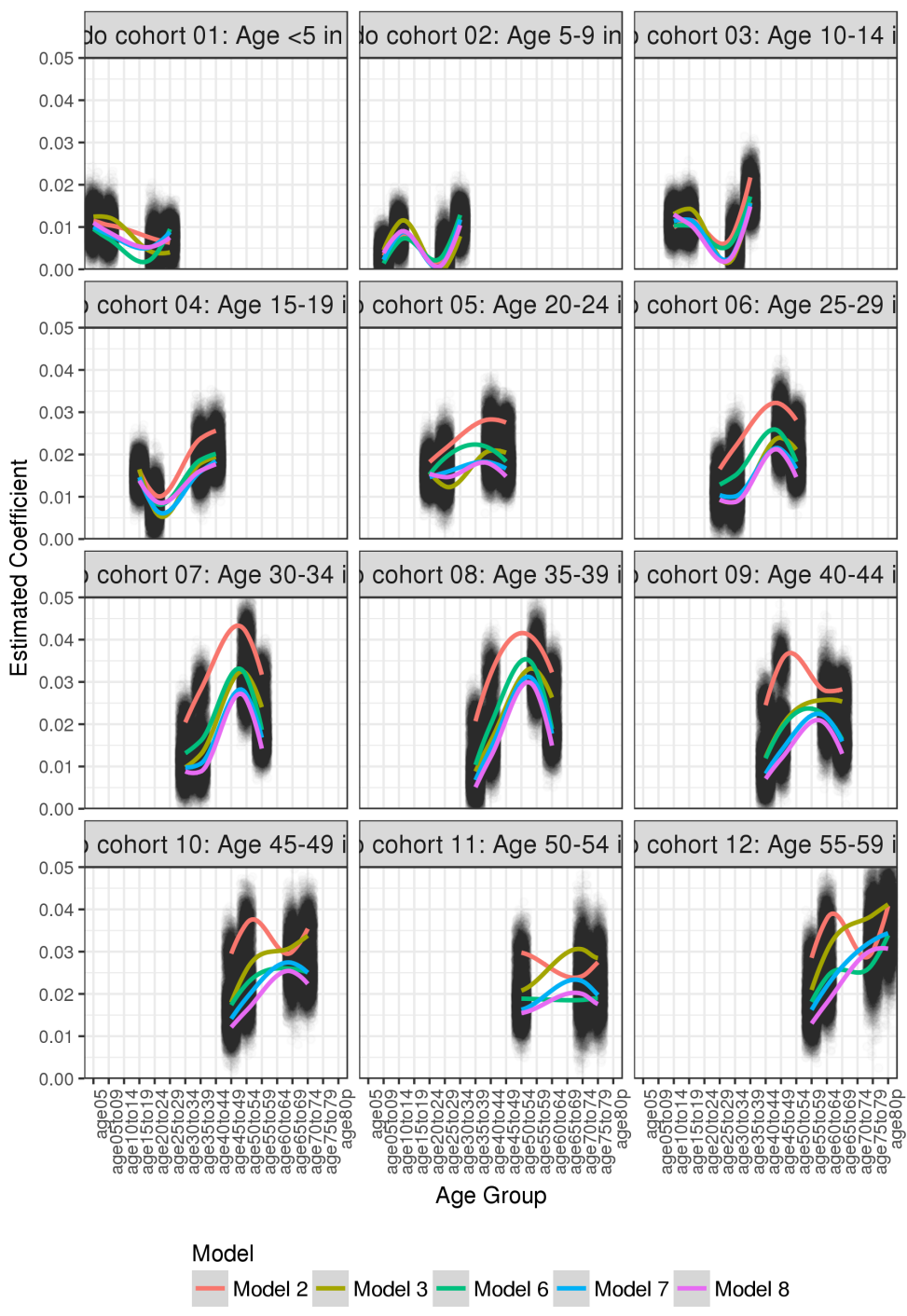

*Model 2: the baseline model (includes local climate variables), Model 3: baseline+income, Model 6: baseline+housing size, Model 7: baseline+income+housing size, Model 8: all predictors.

Figure 4: Comparing micro-profiles across models.

\subsection{Does local climate matter?}

To further evaluate the age-energy consumption profile, we looked at the micro-profiles when the top model was constructed from data from similar climatic regions. All four RECS waves include information about heating- and cooling-degree days (HDD and CDD). We used unsupervised clustering to divide the survey results into three regions of cold, warm, and mild climate. The boundaries fell at the intersection of 2,000 CDD 
and 4,000 HDD, which aligns well with the definition of climate zones by American Institute of Architects (AIA). Survey respondents who lived in an area with less than 2,000 CDD and 4,000 where partitioned into a mild climate region. Those who lived in area with more than 2,000 CDD were assigned to the warm region, and anyone who lived in a region with more than 4,000 HDD was assigned to the cold region. We then fitted the best model separately in each of the climate regions and draw climatespecific age-energy consumption profiles using Generalized Additive Models (GAM) with integrated smoothness estimation on medians - Figure 5.
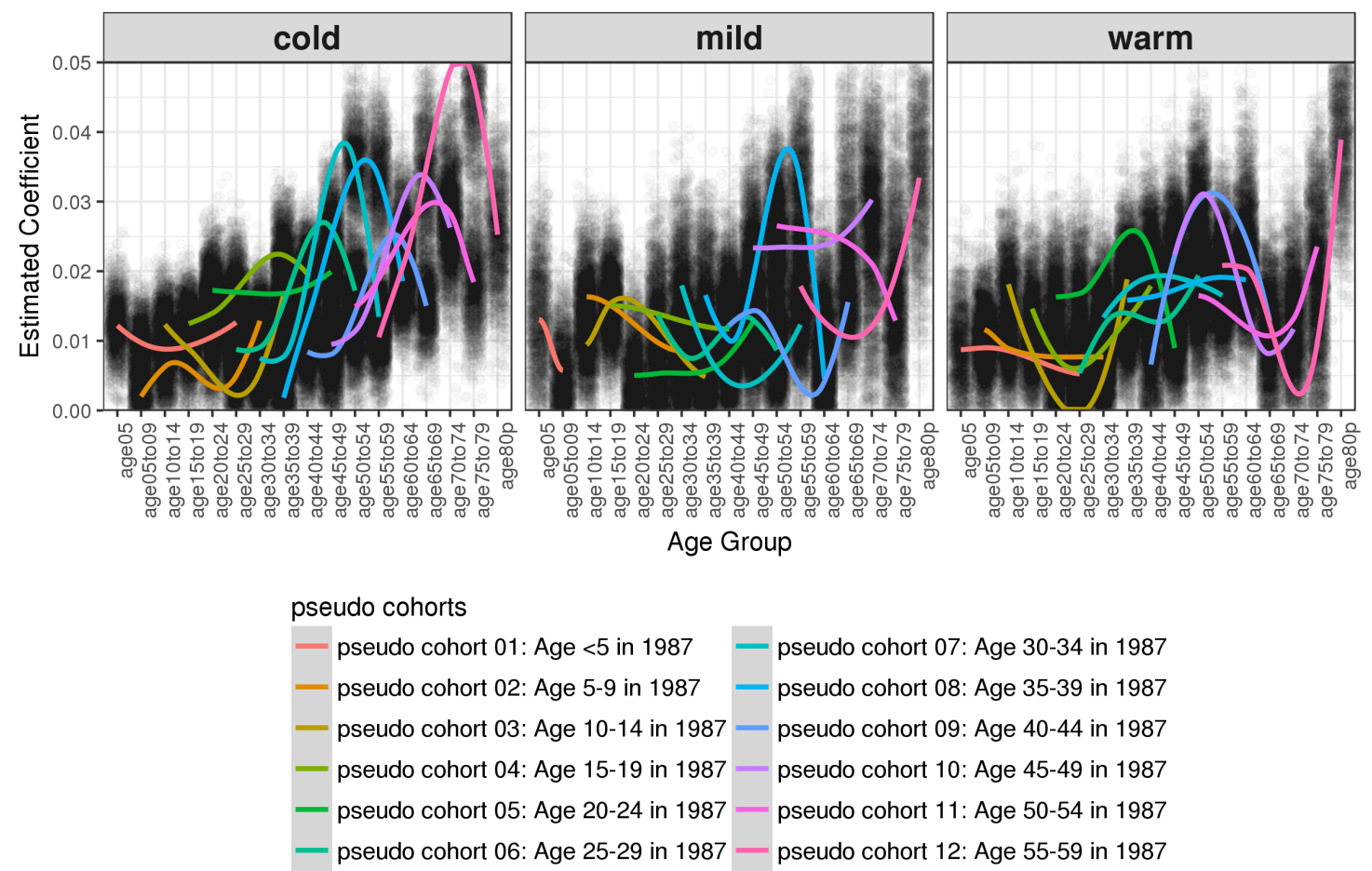

Figure 5: Climate-specific age-energy consumption micro-profiles using obtained from Model 8 in 3 different climate regions.

In general, the age-energy consumption profiles showed a higher energy consumption in the cold region. This finding that supports previous research, is specially highlighted as age increases - i.e., the slope of growth in energy consumption is steeper in cold regions. Besides the fluctuations in the magnitude coefficient estimates (i.e., energy consumption estimates) in micro-profiles, the most prominent climate-induced differences in energy consumption profiles appears to be in the oldest pseudo cohort. First, it appears that energy consumption in the cold region exhibited a concave curve for the oldest; meaning that energy consumption slightly dropped and then rapidly increased after the its surge between ages 45 and 54 . This trend in both cold warm and mild climates is a convex curve. In other words, energy consumption drops in the cold climate from the age group 75-to-79 to 80-plus, whereas in mild and warm climates the overall pattern is increasing. Specifically in the warm climate, energy consumption 
significantly drops after its peak between 45 and 54 , and increases gradually - opposite of the cold climate. It is important to consider the baseline difference for the two climate regions, where in the cold region energy consumption is almost 30 percent higher between the ages of 45 to 54 .

\section{Discussion and Conclusion}

We aimed to explore whether there is an age-energy consumption profile in U.S. residential building, and if so, how housing, income, and local climate might impact the profile. We found an overall increasing profile in energy consumption by age, controlling for income, local climate, and housing age, type, and square footage. There are two periods when the growth in energy consumption over age is slow: (1) before the age of 30, and (2) from 55 to 64 . For the younger pseudo cohorts, this pattern may be due to the formation of a new household (transition from living with parents) and setting a baseline for energy consumption of the new household. Although it may not be technically due to lower income or housing situation, behavioral factors may also contribute to the slightly increasing pattern in energy consumption, compared to the next two decades across the life course. From 30 to 55, there is a rapid increase in energy consumption. Because all age groups, housing, climate, and income are accounted for in the model, such an increase may not be attributed to major life course events, such as addition of new household members. We think that the rapidly increasing energy consumption between 30 and 55 may be due to a general behavioral change in use of energy-consuming goods that may not necessarily correlate with income. In fact, one of our more important findings was that much of the increase in energy consumption after the age of 30 can be attributed to an increase in housing size, which is expected as households grow. However, the fact that after accounting for housing variables the slope is still there suggests that the effects of income and housing characteristics age-energy consumption profile may be intertwined. We also observed that energy consumption increases rapidly after the age of 70 - this pattern was observed after a stabilizing trend between ages of 60 and 70 . This finding suggests that, regardless of income and housing characteristics, consumption of energy increases amongst the elderly.

In our analyses, we also evaluated two potential issues to further ensure the robustness of estimated age-energy consumption profiles. First, we evaluated the possibility of a non-linear relationship between housing size and energy consumption, and its consequent reflection on the age-energy consumption profiles. This was based on the idea that the heat loss in a building is proportional to the area of exposed surface, rather than the area of the building. In this paper, we used square root of housing size (in square feet) to address this potential issue. However, we did not find significant evidence to favor non-linearity against linearity in this case. Second, we studied the possible interaction effects between age groups and local climate variables. We found that in general, the magnitude of energy consumption is higher in cold regions, than 
mild and warm regions. Additionally, between the cold and warm climates, we observed an almost 30 percent difference in energy consumption between ages of 45 to 54 , and a pattern difference for the eldest pseudo cohorts. Nevertheless, we suggest future research efforts on this topic to include investigations about potential local climate effects.

According to data from U.S. Census Bureau, average American single-family homes became over 61 percent larger between 1973 and 2015 [35]. Meanwhile, the average U.S. household has shrunk by more than 15 percent in size [36]. The increasing U.S. homes represent changes in consumption behaviors, as everybody wants their own space and appliances. On the other hand, due to longer life spans and lower birthrates, the U.S. population age pyramid is expected to become a rectangle - with almost identical population distributions across age groups [32]. Our results suggest that the combination of transformation in U.S. population (i.e., population aging) and increases in the average housing size (which individually associates with higher energy demand) will have amplifying effects on the consumption of energy in the U.S. This pattern could happen similarly in other developed or developing countries that have been experiencing low birth rates in recent years.

Population aging has been unfolding in more developed countries for many years. Future population aging trends will move at higher pace in developing countries [15]. Previous literature at the intersection of energy demand, demography, and climate change pointed to potential benefits of population aging for reducing energy demand. Our results contradict these suggestions. Instead, our findings suggest that aging by its own can increase the proportion of population with higher energy consumption. Add to this the amplifying effect of increasing homes sizes and income, both of which directly associate with higher energy consumption.

\section{References}

[1] P. Anker-Nilssen. Household energy use and the environmenta conflicting issue. Applied Energy, 76(1-3):189-196, 92003.

[2] G. Brandon and A. Lewis. Reducing household energy consumption: a qualitative and quantitative field study. Journal of Environmental Psychology, 19(1):75-85, 1999.

[3] D. Brounen, N. Kok, and J. M. Quigley. Residential energy use and conservation: Economics and demographics. European Economic Review, 56(5):931-945, 72012.

[4] A. Carlsson-Kanyama, A.-L. Lindén, and B. Eriksson. Residential energy behaviour: does generation matter? International Journal of Consumer Studies, 29(3):239-253, 52005.

[5] D. L. Costa and M. E. Kahn. Electricity Consumption and Durable Housing: Understanding Cohort Effects, 2011. 
[6] a. Druckman and T. Jackson. Household energy consumption in the UK: A highly geographically and socio-economically disaggregated model. Energy Policy, 36(8):3177-3192, 82008.

[7] H. Estiri. Building and household X-factors and energy consumption at the residential sector. Energy Economics, 43:178-184, 52014.

[8] H. Estiri. The impacts of household behaviors and housing choice on residential energy consumption. PhD thesis, University of Washington, Seattle, 2014.

[9] H. Estiri. A structural equation model of energy consumption in the United States: Untangling the complexity of per-capita residential energy use. Energy Research E Social Science, 6:109-120, 32015.

[10] H. Estiri. The indirect role of households in shaping US residential energy demand patterns. Energy Policy, 86:585-594, 2015.

[11] H. Estiri, A. Krause, and M. P. Heris. Phasic metropolitan settlers: a phasebased model for the distribution of households in US metropolitan regions. Urban Geography, 36(5):777-794, 22015.

[12] R. Ewing and F. Rong. The impact of urban form on U.S. residential energy use. Housing Policy Debate, 19(1):1-30, 12008.

[13] D. J. Fritzsche. An Analysis of Energy Consumption Patterns by Stage of Family Life Cycle. Journal of Marketing Research, 18:227-232, 1981.

[14] O. Guerra Santin, L. Itard, and H. Visscher. The effect of occupancy and building characteristics on energy use for space and water heating in Dutch residential stock. Energy and Buildings, 41(11):1223-1232, 112009.

[15] W. He, D. Goodkind, and P. Kowal. An Aging World: 2015. Technical report, United States Census Bureau, Washington, DC, 2016.

[16] E. Holden and I. Norland. Three challenges for the compact city as a sustainable urban form: Household consumption of energy and transport in eight residential areas in the greater Oslo Region. Urban Studies, 42(12):2145-2166, 112005.

[17] M. Kavgic, a. Mavrogianni, D. Mumovic, a. Summerfield, Z. Stevanovic, and M. Djurovic-Petrovic. A review of bottom-up building stock models for energy consumption in the residential sector. Building and Environment, 45(7):16831697, 72010.

[18] N. Kaza. Understanding the spectrum of residential energy consumption: A quantile regression approach. Energy Policy, 38(11):6574-6585, 112010.

[19] S. Kelly. Do homes that are more energy efficient consume less energy?: A structural equation model of the English residential sector. Energy, 36(9):5610-5620, 92011. 
[20] B. Kriström. Residential Energy Demand. Encyclopedia of Energy, Natural Resource, and Environmental Economics, 1:218-224, 2013.

[21] W. Larson, F. Liu, and A. Yezer. Energy footprint of the city: Effects of urban land use and transportation policies. Journal of Urban Economics, 72(2-3):147159, 92012.

[22] O. Lucon, D. Ürge-Vorsatz, A. Ahmed Zain, H. Akbari, P. Bertoldi, L. Cabeza, N. Eyre, A. Gadgil, L. Harvey, Y. Jiang, E. Liphoto, S. Mirasgedis, S. Murakami, J. Parikh, C. Pyke, and M. Vilariño. Buildings. In O. Edenhofer, R. PichsMadruga, Y. Sokona, E. Farahani, S. Kadner, K. Seyboth, A. Adler, I. Baum, S. Brunner, P. Eickemeier, B. Kriemann, J. Savolainen, S. Schlömer, C. v. Stechow, T. Zwickel, and J. Minx, editors, Climate Change 2014: Mitigation of Climate Change. Contribution of Working Group III to the Fifth Assessment Report of the Intergovernmental Panel on Climate Change, pages 671-738. Cambridge University Press, Cambridge, United Kingdom and New York, NY, USA, 2014.

[23] L. Lutzenhiser. A cultural model of household energy consumption. Energy, 17(1):47-60, 11992.

[24] J. Norman, H. L. MacLean, and C. A. Kennedy. Comparing High and Low Residential Density: Life-Cycle Analysis of Energy Use and Greenhouse Gas Emissions. Journal of Urban Planning and Development, 132:10-21, 2006.

[25] B. C. O'Neill and B. S. Chen. Demographic Determinants of Household Energy Use in the United States. Population and Development Review, 28:53-88, 2002.

[26] P. C. Reiss and M. W. White. Household Electricity Demand, Revisited. Review of Economic Studies, 72(3):853-883, 72005.

[27] S. Roaf, D. Crichton, and F. Nicol. Adapting Buildings and Cities for Climate Change: A 21st Century Survival Guide. Architectural Press, Burlington MA, 2005 .

[28] M. Santamouris, K. Kapsis, D. Korres, I. Livada, C. Pavlou, and M. Assimakopoulos. On the relation between the energy and social characteristics of the residential sector. Energy and Buildings, 39(8):893-905, 82007.

[29] Y. Shimoda, T. Asahi, A. Taniguchi, and M. Mizuno. Evaluation of city-scale impact of residential energy conservation measures using the detailed end-use simulation model. Energy, 32(9):1617-1633, 92007.

[30] K. Steemers and G. Y. Yun. Household energy consumption: a study of the role of occupants. Building Research \& Information, 37(5-6):625-637, 112009.

[31] L. G. Swan and V. I. Ugursal. Modeling of end-use energy consumption in the residential sector: A review of modeling techniques. Renewable and Sustainable Energy Reviews, 13(8):1819-1835, 102009. 
[32] P. T. Taylor. The Next America, 2014.

[33] B. Tonn and J. Eisenberg. The aging US population and residential energy demand. Energy Policy, 35(1):743-745, 12007.

[34] United Nations. World Population Ageing 2015. Technical report, United Nations, Department of Economic and Social Affairs, Population Division, 2015.

[35] U.S. Census Bureau. 2015 Characteristics of New Housing. Technical report, U.S. Department of Commerce, Economics and Statistics Administration, Washington, DC, 2015.

[36] U.S. Census Bureau. Families and Living Arrangements, 2016.

[37] U.S. Energy Information Administration. 1987 RECS Public Use Microdata Files, 2008 .

[38] U.S. Energy Information Administration. 1990 RECS Public Use Microdata Files, 2008 .

[39] U.S. Energy Information Administration. 2005 RECS Survey Data, 2009.

[40] U.S. Energy Information Administration. 2009 RECS Survey Data, 2013.

[41] U.S. Energy Information Administration. International Energy Outlook 2013. Technical report, U.S. Department of Energy, Office of Energy Analysis, Washington, DC, 2013.

[42] I. Vassileva, F. Wallin, and E. Dahlquist. Analytical comparison between electricity consumption and behavioral characteristics of Swedish households in rented apartments. Applied Energy, 90(1):182-188, 22012.

[43] E. Yamasaki and N. Tominaga. Evolution of an aging society and effect on residential energy demand. Energy Policy, 25(11):903-912, 91997.

[44] E. Zagheni. The leverage of demographic dynamics on carbon dioxide emissions: Does age structure matter? Demography, 48(1):371-399, 2011. 